\title{
Developing an adsorption-based gas cleaning system for a dual fluidized bed gasification process
}

\author{
J. Loipersböck ${ }^{1,2}$ (D) $\cdot$ G. Weber ${ }^{1}$ (D) $\cdot$ R. Rauch $^{3}$ (D) H. Hofbauer ${ }^{2}$ (D)
}

Received: 2 March 2020 / Revised: 2 September 2020 / Accepted: 10 September 2020

(C) Springer-Verlag GmbH Germany, part of Springer Nature 2020

\begin{abstract}
Biomass has the potential to make a major contribution to a renewable future economy. If biomass is gasified, a wide variety of products (e.g., bulk chemicals, hydrogen, methane, alcohols, diesel) can be produced. In each of these processes, gas cleaning is crucial. Impurities in the gas can cause catalyst poisoning, pipe plugging, unstable or poisoned end products, or harm the environment. Aromatic compounds (e.g., benzene, naphthalene, pyrene), in particular, have a huge impact on stable operation of syngas processes. The removal of these compounds can be accomplished by wet, dry, or hot gas cleaning methods. Wet gas cleaning methods tend to produce huge amounts of wastewater, which needs to be treated separately. Hot gas cleaning methods provide a clean gas but are often cost intensive due to the high operating temperatures and catalysts used in the system. Another approach is dry or semi-dry gas cleaning methods, including absorption and adsorption on solid matter. In this work, special focus was laid on adsorption-based gas cleaning for syngas applications. Adsorption and desorption test runs were carried out under laboratory conditions using a model gas with aromatic impurities. Adsorption isotherms, as well as dynamics, were measured with a multi-compound model gas. Based on these results, a temperature swing adsorption process was designed and tested under laboratory conditions, showing the possibility of replacing conventional wet gas cleaning with a semi-dry gas cleaning approach.
\end{abstract}

Keywords Gas cleaning $\cdot$ Tar removal $\cdot$ Adsorption $\cdot$ Synthesis $\cdot$ Temperature swing adsorption

\section{Nomenclature}

AC Activated carbon

BET Brunnauer-Emmet-Teller method

BJH $\quad$ Barrett, Joyner, and Halenda procedure

BTX Benzene, toluene, and xylene

$\mathrm{db} \quad$ Dry base

DFB Dual fluidized bed

FAU Faujasite zeolite

FID Flame ionization detector

GC/MS Gas chromatography and mass spectrometry

J. Loipersböck

juergen.loipersboeck@best-research.eu

1 BEST-Bioenergy and Sustainable Technologies, Inffeldgasse 21b, 8010 Graz, Austria

2 Institute of Chemical, Environmental and Bioscience Engineering, TU Wien, Getreidemarkt 9/166, 1060 Vienna, Austria

3 Institute of Chemical, Environmental and Biological Engineering, Karlsruhe Institute of Technology, Engler-Bunte-Ring 1, 76131 Karlsruhe, Germany
GoBiGas Gothenburg biogas plant

PAH Polyaromatic hydrocarbons

RME Rapeseed methyl ester/biodiesel

SCD Sulfur chemiluminescence detector

SEM Scanning electron microscopy

STP Standard temperature and pressure

$\left(273.15 \mathrm{~K}, 10^{5} \mathrm{~Pa}\right)$

TGA Thermogravimetric analysis

TSA Temperature swing adsorption

$b(T) \quad$ Langmuir coefficient

$\Delta H_{\text {ads }} \quad$ Adsorption enthalpy

$m_{\mathrm{AC}} \quad$ Mass AC

$m_{\mathrm{AC}}$, in $\quad$ Mass $\mathrm{AC}$ at beginning of adsorption experiment

$m_{\mathrm{AC} \text {, out }} \quad$ Mass $\mathrm{AC}$ after adsorption experiment

$p_{i} \quad$ Partial pressure

$R \quad$ Gas constant

$t_{\mathrm{BT}} \quad$ Breakthrough time

$X_{\text {ads }} \quad$ Adsorption capacity

$X_{\mathrm{BT}} \quad$ Adsorption capacity at the tar breakthrough point

$X_{\text {mon }} \quad$ Monomolecular loading

$Y(t)_{\text {ads }} \quad$ Adsorbed amount of tar in dependency to the time 
$Y_{\text {in }} \quad$ Tar inlet concentration

$Y(t)_{\text {out }} \quad$ Tar outlet concentration in dependency to the time

\section{Introduction}

The use of biomass in sustainable technologies is key to a renewable future. As the only renewable carbon source, a strong focus should be on the development of renewable processes for the production of carbon-based chemicals.

Dual fluidized bed (DFB) gasification is used to produce a high caloric, nitrogen-lean product gas. With this product gas, several syntheses, like Fischer-Tropsch, mixed alcohols, methanation, and hydrogen production, can be realized. Nevertheless, an efficient gas cleaning system is crucial for these downstream processes. Nitrogen- (e.g., ammonia, hydrocyanic acid), halogen- (e.g., hydrochloric acid), and sulfur- (e.g., $\mathrm{H}_{2} \mathrm{~S}$, COS, mercaptans) based impurities, as well as high molecular hydrocarbons (tar), can cause problems in the catalytic reaction. Therefore, they must be removed from the gas before it is usable in synthesis gas (syngas) processes. To lower the total amount of tar, DFB gasifiers are operated at higher temperatures, leading to the reduction of total tar but enhancing the formation of higher aromatics and polyaromatic hydrocarbons $(\mathrm{PAH})$ due to the reduction of oxygen in the structures [1-7]. Hydrogen is well known for tar reduction and reduces the formation of heavier tars. With increasing temperature, higher molecular tars are formed. As tar formation is not the topic of this work, please refer to previous works on the topic [8-12].

To remove these problematic compounds, several approaches exist. They can be divided into primary and secondary methods. As primary methods are not the scope of this work, please refer to previous works on this topic [1-7]. Secondary methods can be divided into wet scrubbing (e.g., baffle separators, cooling towers, or venturi scrubbers), dry or semi-dry methods (e.g., Ab-/adsorption on solids, particle cyclones, cold filters), and hot gas conditioning methods (e.g., hot filters, thermal and catalytic crackers, steam reformers) [12]. As wet tar removal methods tend to produce high amounts of wastewater and hot gas methods are cost intensive, this work focuses on dry methods, especially adsorption.

Thiophene removal from an oily phase, as well as tar separation during the thiophene syntheses, is well studied. Jeevanandam et al. studied thiophene removal from hydrocarbons using metal-impregnated adsorbents. Yu et al. worked on the desulfurization (especially thiophene and dibenzothiophene) of oil using activated carbon (AC) [13, 14]. Edinger et al. investigated thiophene removal from the gaseous phase using AC as a low-temperature alternative to hydro-desulfurization at temperatures between 100 and $200{ }^{\circ} \mathrm{C}[15]$.
Several studies concerning the removal of tar from biomass gasifier gas have been completed, focusing on gas cleaning for heat and electric power production [16-18].

Further gas cleaning technology is employed in the Gothenburg Biogas plant (GoBiGas), where a four-adsorber system is used to remove heavy tars, BTX (benzene, toluene, xylene), and sulfur components to achieve syngas quality suitable for methanation after a biodiesel scrubber [19, 20]. This paper describes the development of adsorption-based gas cleaning to upgrade gasifier gas to syngas quality using adsorption technology.

\section{Concept and methodology}

At the laboratory scale, a gas cleaning unit was investigated, focusing on the reduction of operating costs by replacing costly gas scrubbing using biodiesel (RME) by adsorption on AC. Therefore, tar analysis, obtained from industrial DFB gasifiers, was used to select model tar components. A classification of tars was introduced to represent each class in the mixture. With this model tar, experimental research, in terms of adsorption and desorption behavior, was carried out. Due to economic considerations, this paper focuses on fine gas cleaning (substitution of the second biodiesel scrubber, see Fig. 1), as it has a 10 times higher biodiesel consumption compared with the first biodiesel scrubbing stage [21].

\subsection{DFB steam gasification}

DFB steam gasification is an allothermal gasification technology, using steam as a gasification agent. Two reaction zones, coupled by a slide and cyclone, are applied for this process. A steam-fluidized reactor is used to gasify biomass in a bubbling bed. Fuel reacts with steam in the presence of catalytic active bed material under consumption of heat to the main gas components: hydrogen, carbon monoxide, carbon dioxide, and methane [22]. The non-gasified biomass and bed material are transported over a slide to the combustion zone. There, a fast, fluidized bed is applied by fluidization with air. The nongasified biomass is burned, and the bed material is heated up again. Through a cyclone, bed material is separated from the flue gas stream and transported back into the gasification reactor. The resulting gasification product is an almost nitrogenfree gas that is well suited for syngas applications, like hydrogen production, Fischer-Tropsch synthesis, or methanation.

For use in syngas applications, impurities must be removed. Impurities can be hydrogenated over the water gas shift stage or removed by a two-stage biodiesel scrubbing unit [23, 24], which is state-of-the-art in biomass-to-chemical processes. Figure 1 shows the gas cleaning setup of a Fischer-Tropsch plant based on DFB gasification of wood. The two-stage scrubber (biodiesel scrubber "warm" and biodiesel scrubber "cold") 
Fig. 1 Flow chart of DFB-based syngas plant gas cleaning

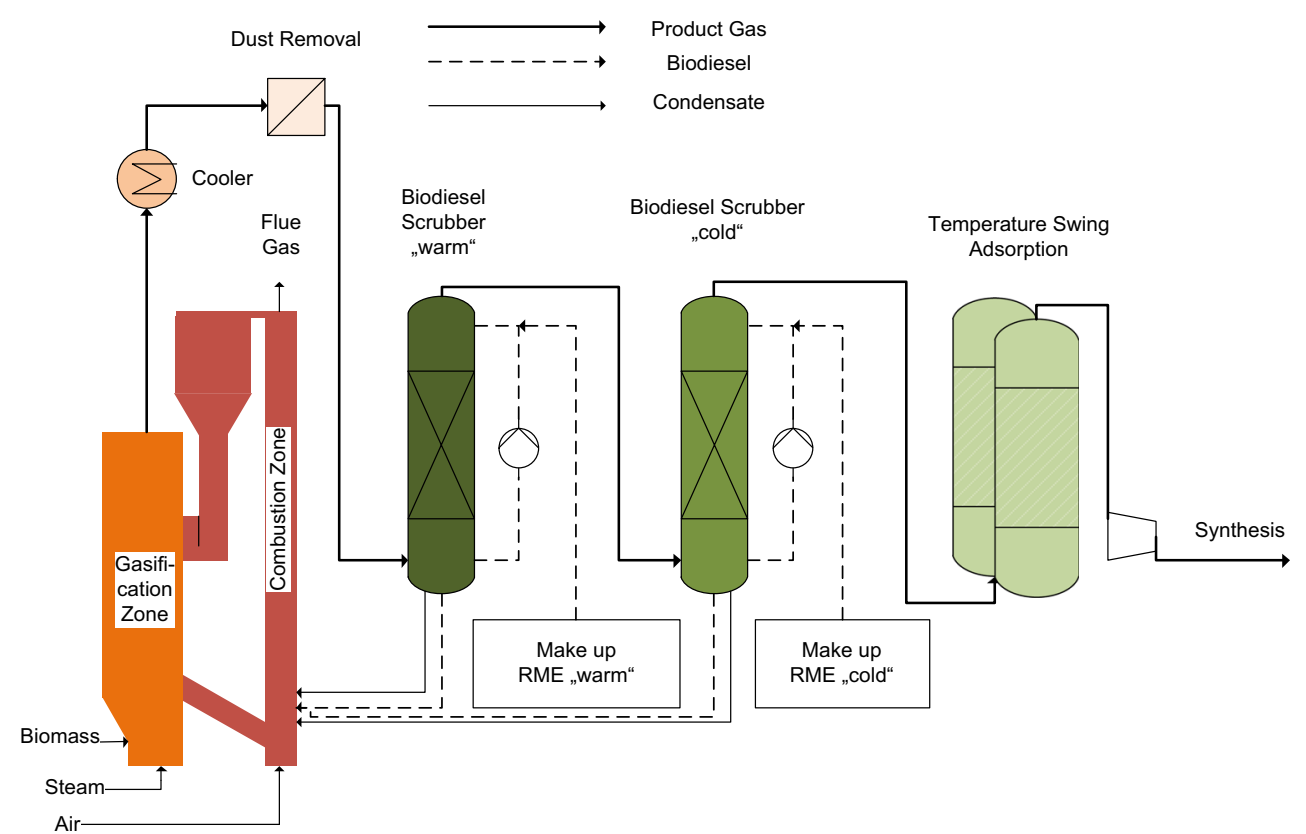

allows almost complete removal of tar components. Temperature swing adsorption (TSA) is used to remove high volatile hydrocarbons, as well as sulfur components.

Thus, gas cleaning by scrubbing is expensive; a more costfriendly method must be developed. Table 1 shows impurity amounts in syngas before and after the first biodiesel scrubber stage (biodiesel scrubber "warm," Fig. 1). High removal efficiency of gravimetric tars and poor removal efficiency of BTX components can be observed. Applying a two-stage biodiesel scrubber leads to high biodiesel consumption, even if the solvent is regenerated [21].

Therefore, an adsorption-based gas cleaning unit is being developed. The biodiesel scrubber "cold" is replaced by a TSA to remove tar and sulfur components more efficiently. To design a TSA, a detailed investigation of tar behaviors during adsorption and desorption processes was carried out.

\subsection{Classification of tars}

As tar characterization has been part of several research projects, many classification systems exist. Baker et al. [28]

Table 1 Impurities before and after the first biodiesel scrubber stage [25-27]

\begin{tabular}{lll}
\hline & Inlet scrubber & Outlet scrubber \\
\hline $\mathrm{H}_{2} \mathrm{O}($ vol-\%) & $35-45$ & $8-12$ \\
Gravimetric tar $\left(\mathrm{g} / \mathrm{m}^{3}{ }_{\text {STP }}\right)(\mathrm{db})$ & $2-5$ & $0-0.2$ \\
$\mathrm{BTX}\left(\mathrm{g} / \mathrm{m}^{3}\right.$ STP $)(\mathrm{db})$ & $15-20$ & $5-15$ \\
Sulfur components $(\mathrm{ppm})$ & $175-250$ & $150-250$ \\
$\mathrm{NH}_{3}(\mathrm{ppm})$ & $200-1500$ & $100-400$ \\
\hline
\end{tabular}

define tars by their formation in primary, secondary, and tertiary tar. However, this characterization does not include chemical properties or specific compound classes, such as organic acids. Furthermore, tar can be defined as organic components with a boiling point higher than benzene, and classification distinguishing by gravimetric and GC/MS tar exists, as well [12, 29-32]. Another method for tar classification is characterization by molecular weight and physical properties, defining five classes. Class 1 tars are described as gravimetric tars. Class 2 tars are heterocyclic tars with high solubility in water, with a typical representative compound being phenol. Class 3 tars are light aromatics, like toluene, and they are described as single-ring components. Class 4 tars are light PAH (2-3-ring structures), like naphthalene. Class 5 tars have a polyaromatic structure of 4-7 rings (e.g., pyrene) [32]. One definition states that long-chain hydrocarbon compounds having a larger molar mass than benzene $(78.1 \mathrm{~g} / \mathrm{mol})$ can be referred to as tar [33]. The tar protocol defines tar as the total of all organic compounds in the synthesis gas, with the exception of permanent gaseous hydrocarbons and benzene [32, 33]. Another definition describes tar as the condensable fraction of organic gasification products and aromatic hydrocarbons, including benzene [34].

As the aim of this work was to clean a gas to syngas quality, the removal of benzene, due to its condensability during compression, is highly recommended. Therefore, the classification system using five tar classes [32], including benzene as a class 3 tar, was applied. Based on the classification approach with five tar classes and the measured tar quality and quantity after the biodiesel scrubber (warm), a model gas composition was selected. Tar sampling was executed according to the tar protocol [33]. 


\subsection{Selection of model tar compositions}

After biodiesel scrubbing, the model tar consisted of thiophene, representing aromatics with a hetero atom; toluene, representing the BTX fraction; styrene, representing aromatics; and naphthalene, representing light polycyclic aromatics. Class 5 tars were not considered, as they are removed in the first biodiesel scrubbing stage. Table 2 depicts the model tar composition. This mixture has a tar dew point of $38.9^{\circ} \mathrm{C}$ at concentrations of $25.91 \mathrm{~g} / \mathrm{m}^{3}$ STP, which represents the tar dew point of DFB syngas after one-stage biodiesel scrubbing [21].

\subsection{Activated carbon}

A commercially available activated charcoal was used for experiments. This coal has a bulk density of $500 \mathrm{~kg} / \mathrm{m}^{3}$. To operate in a small lab reactor, the $\mathrm{AC}$ was crushed and sieved to obtain a pellet diameter between $0.5-1.6 \mathrm{~mm}$. The AC was dried at $105{ }^{\circ} \mathrm{C}$ for $48 \mathrm{~h}$ to exclude side effects caused by different water content in the AC. Approximately $1 \mathrm{~kg}$ of this $\mathrm{AC}$ was prepared as described above. As measured by the Brunnauer-Emmet-Teller (BET) surface method, an inner surface between 890 and $940 \mathrm{~m}^{2} / \mathrm{g}$ was determined for the examined AC. The Barrett, Joyner, and Halenda (BJH) method indicated a pore size between 3.1 and $3.5 \mathrm{~nm}$ (adsorption/ desorption). An average pore volume of $0.13-0.19 \mathrm{~cm}^{3} / \mathrm{g}$ (desorption/adsorption) was determined by the BJH method, and the pore width, according to the BET method, was $2.1 \mathrm{~nm}$. Measurements of pore size, pore volume, and BET surface were done with a TriStar II 3020 analyzer. To characterize the surface further, scanning electron microscopy (SEM) was done.

\subsection{Adsorption setup and design of experiments}

To develop efficient gas cleaning for syngas applications, several adsorption experiments were executed. Figure 2 shows the flow chart of the adsorption test rig used for experiments. A mass flow controller (MFC) from Voegtlin was applied to adjust the proper carrier gas flow. A syringe pump from Cole Parmer was used to adjust the amount of water and tars fed into the system. These two streams were mixed in an evaporation column situated in an oven (Binder). The mixture was

Table 2 Model tar composition after the first biodiesel scrubber stage

\begin{tabular}{lcl}
\hline & Tar composition (\%) & Tar class \\
\hline Thiophene & 0.3 & 2 \\
Toluene & 85.4 & 3 \\
Styrene & 7.1 & 3 \\
Naphthalene & 7.2 & 4 \\
\hline
\end{tabular}

sent to an adsorber, also in the oven, to guarantee a stable temperature. After the gas left the adsorber, several measurements were carried out. Tar components with the boiling point of naphthalene or below were measured directly via gas chromatography with a flame ionization detector (FID). Sulfur components (thiophene) were also measured by gas chromatography with a sulfur chemiluminescence detector (SCD). Adsorption behavior, in terms of adsorption isotherms and isobars, was determined experimentally and described by a Langmuir isotherm approach. As adsorption reactor, a stainless-steel cylinder with an inner diameter of $9 \mathrm{~mm}$ and height of $50 \mathrm{~mm}$ was used. A superficial velocity of $0.1 \mathrm{~m} / \mathrm{s}$ was adjusted. Each measurement point was measured multiple times. Adsorption isotherms were established at a standard temperature of $40{ }^{\circ} \mathrm{C}$ by varying the inlet tar concentration between 1.5 and $50 \mathrm{~g} / \mathrm{m}^{3}$ STP. Adsorption isobars were measured by adjusting a constant tar concentration of $25.91 \mathrm{~g} /$ $\mathrm{m}^{3}$ STP and varying the temperature between 40 and $220{ }^{\circ} \mathrm{C}$.

For both adsorption isotherms and isobars, the adsorption capacity $\left(X_{\text {ads }}\right)$ was calculated after full loading by Eq. (1), where $m_{\mathrm{AC} \text {,in }}$ is the mass of the $\mathrm{AC}$ at the beginning of the experiment and $m_{\mathrm{AC} \text {,out }}$ is the mass of at the end of the experiment.

$X_{\mathrm{ads}}=\frac{m_{\mathrm{AC}, \text { out }}-m_{\mathrm{AC}, \text { in }}}{m_{\mathrm{AC}, \text { in }}}$

Based on the measured adsorption capacity, adsorption isotherms were determined experimentally and validated with a single component Langmuir adsorption isotherm model, described in Eq. (2), where $X(T)$ is the temperature depending adsorption capacity, $X_{\text {mon }}$ is the monomolecular loading, $b(T)$ is the Langmuir coefficient, and $p_{i}$ the partial pressure of the adsorptive A non-linear regression was applied to fit the model to the measured data.

$X(T)=X_{\operatorname{mon}} \frac{b(T) p_{i}}{1+b(T) p_{i}}$

For a more accurate result of adsorption (or desorption) enthalpy, the Clausius-Clapeyron Eq. (3) was applied, where $\Delta H_{\text {ads }}$ is the adsorption enthalpy, $R$ is the gas constant, and $p$ is the partial pressure at different temperatures $T$. $[35,36]$

$\ln \frac{p_{2}}{p_{1}}=\frac{\Delta H_{\mathrm{ads}}}{R}\left(\frac{1}{T_{1}}-\frac{1}{T_{2}}\right)$

Adsorption dynamics were measured at tar concentrations of $25.91 \mathrm{~g} / \mathrm{m}^{3}$ STP by monitoring the total tar amounts fed into the system and leaving the system. The difference between inlet and outlet tar amounts was defined as the adsorbed tar amount (Eq. 4), where $Y(t)_{\text {ads }}$ is the adsorbed tar amount in dependency to the time, $Y_{\text {in }}$ is the tar inlet concentration, and $Y(t)_{\text {out }}$ is the tar outlet concentration in dependency to time. 
Fig. 2 Flow chart of the lab test setup
$\begin{array}{lllll}\mathbf{N}_{\mathbf{2}} & \mathrm{CO} & \mathrm{CO}_{2} & \mathrm{H}_{2} & \text { Syngas }\end{array}$

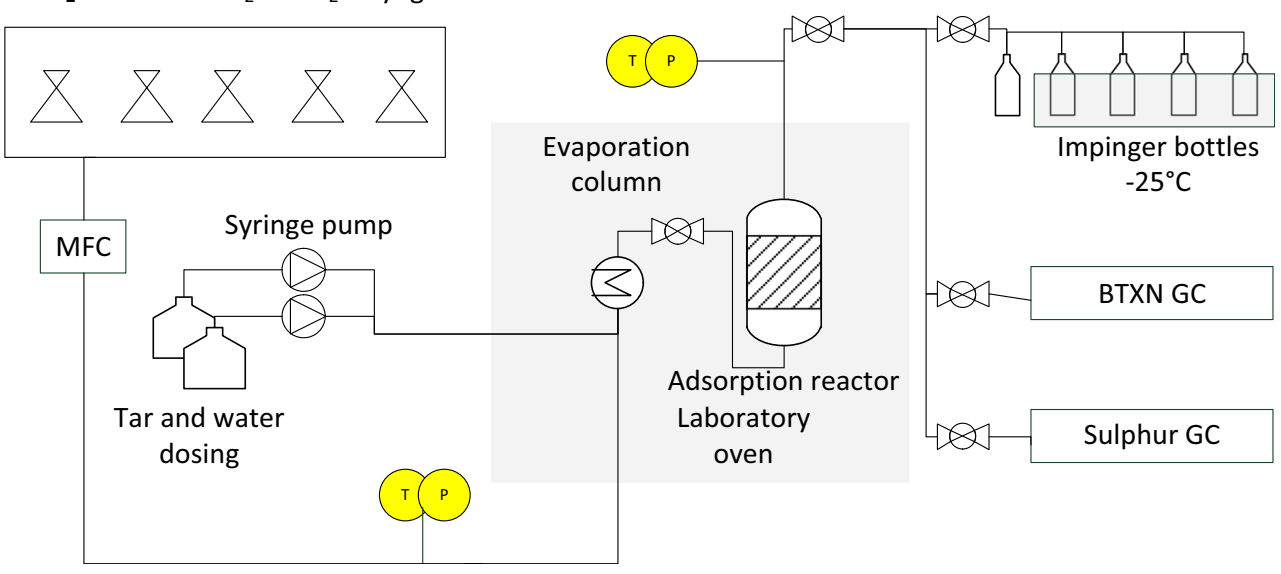

$Y(t)_{\mathrm{ads}}=Y_{\mathrm{in}}-Y(t)_{\mathrm{out}}$

Also, thiophene adsorption dynamics were measured by analyzing the outlet gas in a SCD gas chromatograph. Based on adsorption dynamics, the specific tar adsorption amount $\left(X_{\mathrm{BT}}\right)$ was calculated using the breakthrough time $\left(t_{\mathrm{BT}}\right)$, the mass of the adsorbent $\left(m_{\mathrm{AC}}\right)$, and the tar inlet concentration ( $Y_{\text {In }}$ Eq. 5).

$X_{B \mathrm{~T}}=\frac{Y_{\text {in }} t_{\mathrm{BT}}}{m_{\mathrm{AC}}}$

Based on these data, the adsorption portion of TSA was designed.

\subsection{Desorption setup and design of experiments}

To investigate the desorption behavior, loaded AC was used and investigated by thermogravimetric analysis (TGA). In TGA, a temperature ramp was adjusted to measure the mass reduction of $\mathrm{AC}$ over time and desorption of tars. The temperature, where the highest mass loss occurred, was defined as the characteristic temperature.

\section{Results and discussion}

\subsection{Characterization of the examined AC}

The investigated AC was tested in terms of BET surface, pore width, pore volume, and by SEM. A blank test, fully-loaded $\mathrm{AC}$, which was used to determine the adsorption capacity at a tar loading of $25.91 \mathrm{~g} / \mathrm{m}^{3}$ (STP), and an AC, which was unloaded in the TGA experiment, were investigated. Table 3 summarizes these results. The blank test had the highest surface area of the investigated ACs. The loaded AC had a surface area of $349 \mathrm{~m}^{2} / \mathrm{g}$. The adsorption pore widths obtained by the BET method did not differ significantly. The blank test showed a pore width of $2.1 \mathrm{~nm}$. The loaded AC showed a pore width of $2.5 \mathrm{~nm}$, and the unloaded (TGA) showed a pore width of $2.2 \mathrm{~nm}$. Similar findings were seen when comparing the BJH diameters. The total pore volume of the blank test and unloaded AC (TGA) did not differ at all. The loaded AC showed, subsequently, a lower pore volume due to its loading with tar components.

Figure 3 shows SEM analysis of the examined AC. (a) and (b) show a blank test of investigated AC before adsorption at resolutions of 100 and $10 \mu \mathrm{m}$, respectively. A homogenous surface was observed, indicating high carbon content and low impurity content on the AC. (c) and (d) show the AC after several (100) hours of TSA operation. The sample was taken after the desorption phase, which was operated at $180^{\circ} \mathrm{C}$ to be comparable with the blank test. The blank test (a,b) and the AC after TSA operation (c, d) look identical from an optical point of view. Both SEM images show very little impurity content and homogenous surfaces, indicating efficient desorption.

\subsection{Adsorption}

Adsorption isotherms were measured to describe the adsorption behavior of $\mathrm{AC}$ used to remove tar components from syngas. Figure 4 shows the adsorption isotherm measured at $40{ }^{\circ} \mathrm{C}$. This isotherm correlates with pure toluene adsorption at similar temperatures. A Langmuir model (Eq. 2) was applied to describe the adsorption isotherm. Adsorption isobars were measured at $40,65,85$, and $180{ }^{\circ} \mathrm{C}$. Based on these measurements and fitting the Langmuir model, adsorption isotherms for 65,85 , and $180{ }^{\circ} \mathrm{C}$ were calculated and are shown in Fig. 4. These isotherms were validated at other temperatures and show good correlation at higher tar concentrations (20-30 g/m ${ }_{\text {STP }}^{3}$ ) and higher deviation at low tar concentrations. A maximum error of $20 \%$ was obtained at low tar concentrations. Based on the adsorption isotherms, the Clausius-Clapeyron equation was used to calculate adsorption enthalpy. An adsorption enthalpy of $93 \mathrm{~kJ} / \mathrm{mol}$ was calculated 
Table 3 Characterization of the raw $\mathrm{AC}$, loaded $\mathrm{AC}$, and $\mathrm{AC}$ after desorption in a TGA experiment

\begin{tabular}{llll}
\hline Analyze/sample & Blank test & Loaded AC & TGA experiment \\
\hline Surface $(B E T)\left(\mathrm{g} / \mathrm{m}^{2}\right)$ & 890 & 349 & 829 \\
Adsorption pore width (BET) $(\mathrm{nm})$ & 2.1 & 2.5 & 2.2 \\
BJH adsorption diameter $(\mathrm{nm})$ & 3.1 & 3.3 & 3.2 \\
BJH desorption diameter $(\mathrm{nm})$ & 3.5 & 3.6 & 3.4 \\
BJH adsorption pore volume $\left(\mathrm{cm}^{3} / \mathrm{g}\right)$ & 0.19 & 0.15 & 0.19 \\
BJH desorption pore volume $\left(\mathrm{cm}^{3} / \mathrm{g}\right)$ & 0.13 & 0.10 & 0.14 \\
\hline
\end{tabular}

for the desired process parameters. This value is highly dependent on the process temperature and inlet tar concentration. The measured value correlates with literature data [35-37].

The adsorption dynamics were measured by a gravimetric approach. The amount (mass) of tar injected into the system was adjusted with a syringe pump, and the mass increase of the adsorbent was measured. Figure 5 shows the breakthrough curve measured gravimetrically. The theoretical mass increase (inlet) and mass increase of the adsorbent were similar until a maximum loading of the adsorbent was reached. A maximum adsorption capacity of $0.34 \mathrm{~g}_{\mathrm{tar}} / \mathrm{g}_{\mathrm{AC}}$, or $34 \%$, was measured. Based on this data, a specific tar adsorption of $0.30-0.33 \mathrm{~g}_{\mathrm{tar}} /$ $\mathrm{g}_{\mathrm{AC}}$ was calculated from several experiments. Nevertheless, this approach gave no information about the outlet concentration of the components. Therefore, thiophene content was analyzed.

Based on the findings above, the sum tar and thiophene concentrations were measured separately. Figure 6 shows breakthrough curves of the whole tar mixture and thiophene.
The breakthrough curves show deviations in breakthrough time. As thiophene is a minor component of the gas, it does not contribute significantly to the gravimetric breakthrough curve. A concentration of 25-ppm thiophene was adjusted at the inlet of the system, and a complete breakthrough of thiophene was detected after $50 \mathrm{~min}$, which is similar to the start of breakthrough measured at the tar breakthrough curve. However, a further thiophene increase beyond the feed concentration was measured and indicated displacement effects. Comparing the thiophene breakthrough curve with the tar breakthrough curve showed that thiophene fully breaks through when $\mathrm{AC}$ reaches the maximum loading. Further loading of AC leads to displacement effects, and thiophene is desorbed and replaced by hydrocarbons with higher evaporation temperatures.

$\mathrm{Hu}$ et al. described displacement effects with a phenol, ocresol, naphthalene, and 1-methylnaphthalene mixture at an elevated temperature of $150{ }^{\circ} \mathrm{C}$. At this temperature, tars with methyl groups tended to adsorb more effectively compared
Fig. 3 SEM analysis of AC before $(a, b)$ and after (c, d) TSA operation at resolutions of 100 (a, c) and $10 \mu \mathrm{m}(\mathrm{b}, \mathrm{d}) .(\mathrm{c})$ and (d) show AC after several (100) hours of TSA operation. Samples were taken after a regeneration cycle
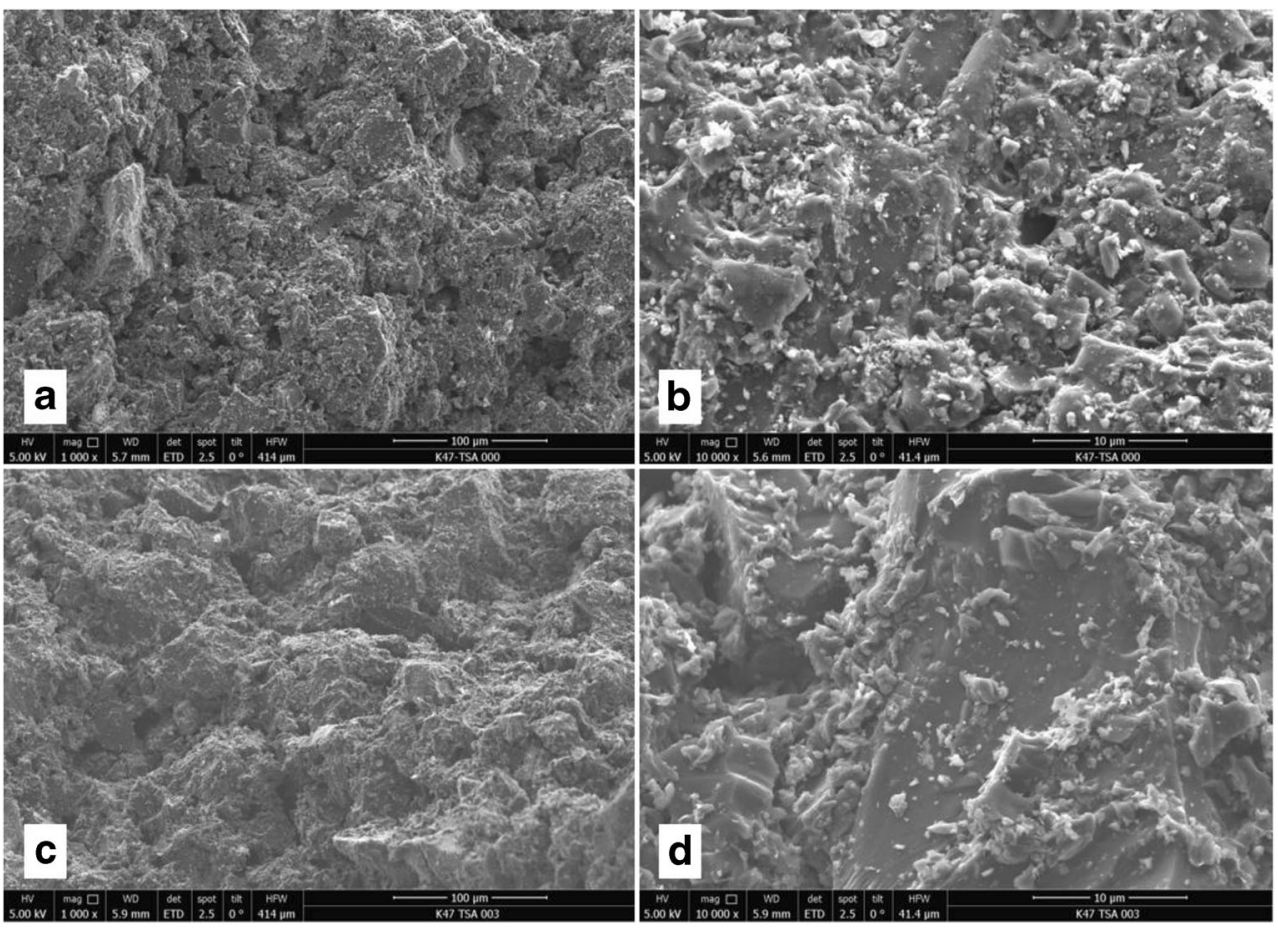


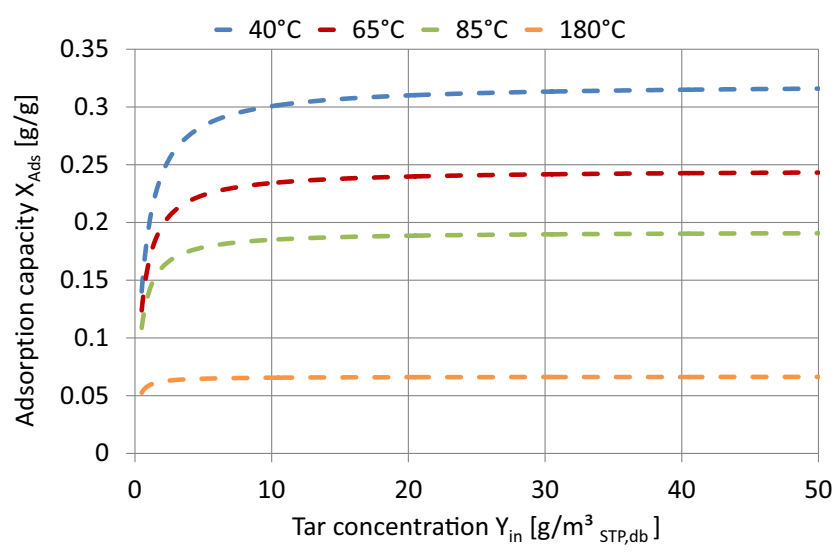

Fig. 4 Adsorption isotherms at different temperatures

with non-methyl group species. Also, tars with higher boiling points were adsorbed more efficiently than tars with lower boiling points. This correlates with findings in this work describing thiophene displacement [17].

Dang et al. investigated adsorption isotherms of benzene and thiophene for siliceous faujasite (FAU) zeolite at $27^{\circ} \mathrm{C}$. Single-component isotherms show Langmuir characteristics. Also, a binary mixture of benzene and thiophene showed Langmuir characteristics for benzene. However, thiophene showed poor adsorption capacity when mixed with benzene, indicating displacement effects [38].

\subsection{Desorption}

Desorption behavior was analyzed by TGA experiments. Several temperature ramps, from 20 to $700{ }^{\circ} \mathrm{C}$, were measured. Test runs with a heating ramp of $5{ }^{\circ} \mathrm{C} / \mathrm{min}$ were carried out. A maximum mass decrease was observed at $152{ }^{\circ} \mathrm{C}$. Figure 7 shows the TGA curve, including variation with a temperature range of 30 to $700{ }^{\circ} \mathrm{C}$ and heating ramp of $5{ }^{\circ} \mathrm{C} / \mathrm{min}$. Based on the characterizing temperature and adsorption properties, a TSA was designed and operated.

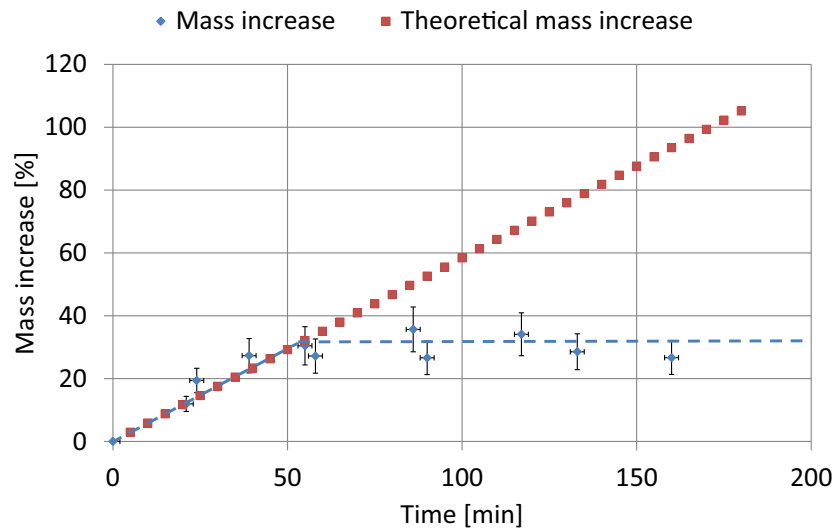

Fig. 5 Theoretical mass increase (red) and mass increase of AC during operation (blue)

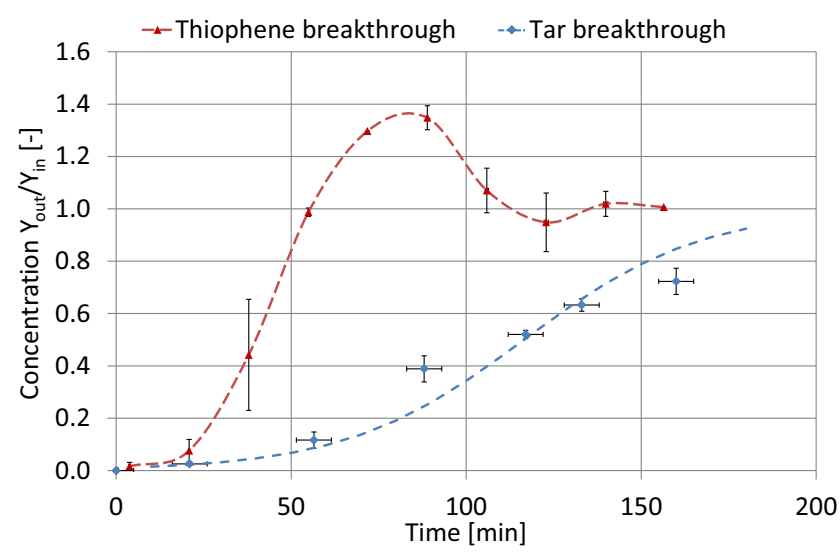

Fig. 6 Tar (blue) and thiophene (red) breakthrough curve normalized to the input concentrations

\subsection{TSA}

The designed TSA was operated at an adsorption temperature of $40{ }^{\circ} \mathrm{C}$ and tar concentration of $25 \mathrm{~g} / \mathrm{m}^{3}$ STP. Desorption temperatures of 180 and $152{ }^{\circ} \mathrm{C}$ were tested. The TSA was operated with the same setup described for adsorption experiments. The calculated adsorption capacity of $0.3-0.33-\mathrm{g}$ adsorbable tar per 1-g AC was demonstrated by several experiments.

Figure 8 ( $a$ and $b$ ) depicts the performance of the designed TSA at a $180^{\circ} \mathrm{C}$ desorption temperature over the first (a) and fifth (b) days of operation. The tar removal efficiency during the adsorption reached $99 \%$. After $100 \mathrm{~h}$ of operation, a slight decrease in tar removal efficiency was observed. However, a minimum tar removal of $96 \%$ was measured after $117 \mathrm{~h}$ of operation. Good tar removal performance, which shows the possibility of using such a setup for tar removal in synthesis processes, is indicated.

Figure 8 ( $\mathrm{c}$ and d) shows the performance of TSA at a $152{ }^{\circ} \mathrm{C}$ desorption temperature over the second (c) and seventh (d) days of operation. During the desorption phase $\left(152{ }^{\circ} \mathrm{C}\right)$, tar components were desorbed, and the adsorbent was regenerated. During the adsorption phase $\left(40^{\circ} \mathrm{C}\right)$, tar

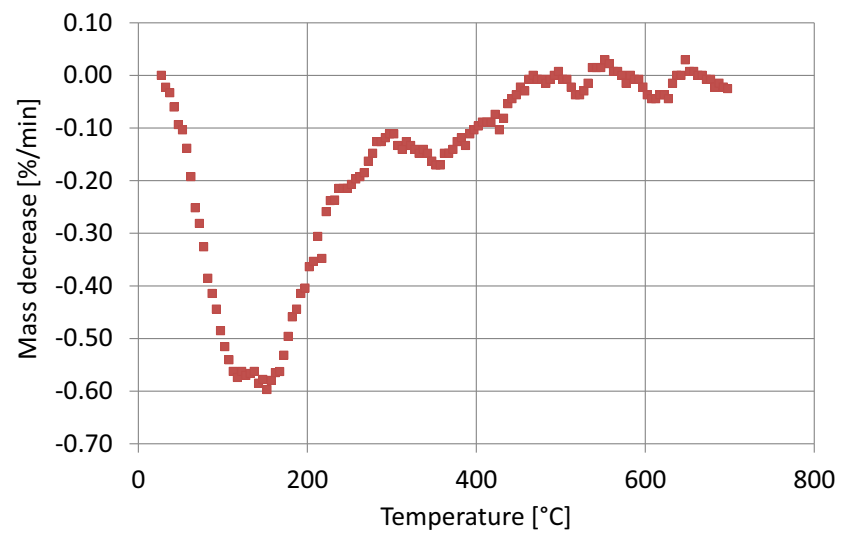

Fig. 7 Differential mass loss of the loaded AC in a TGA analyzer 

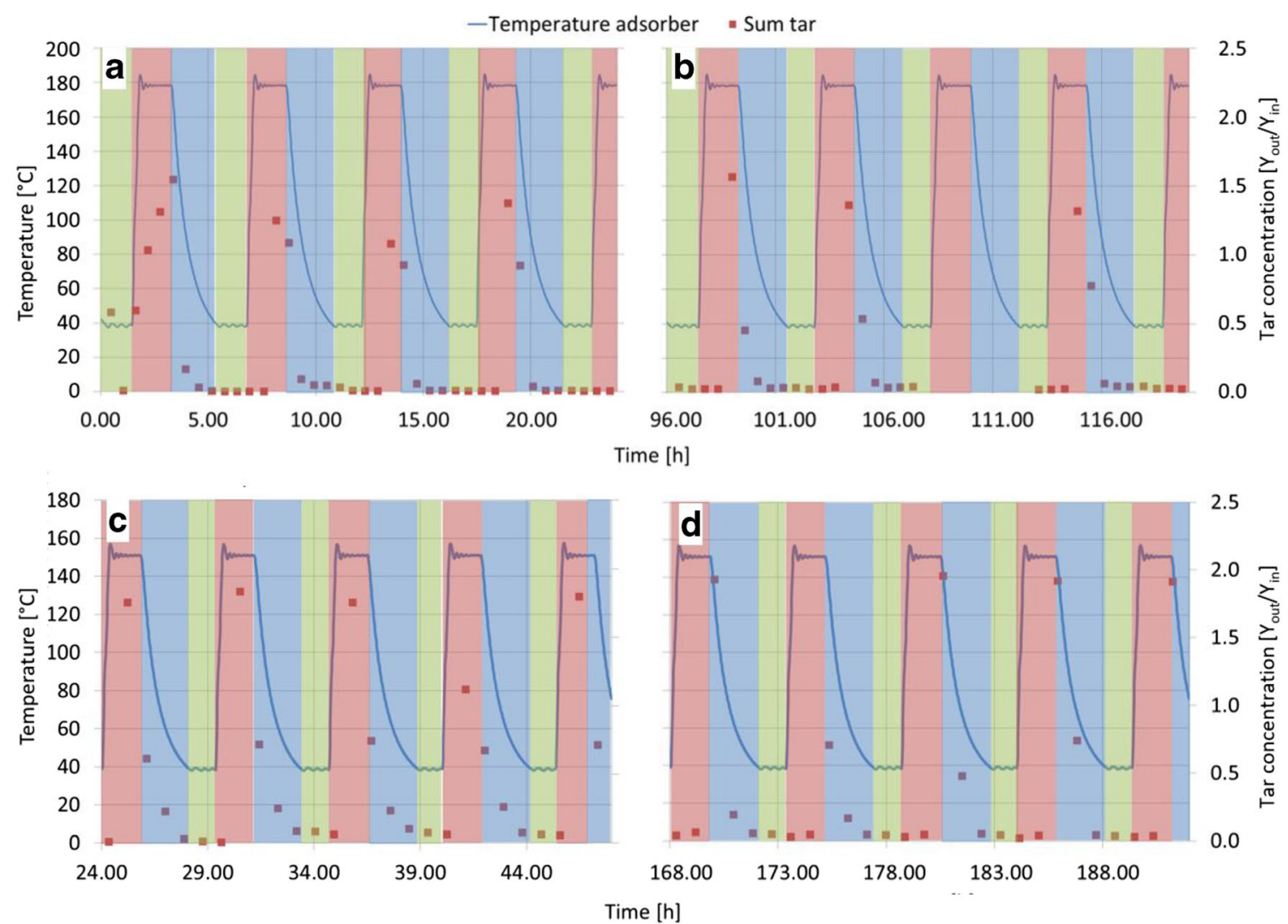

Fig. 8 TSA performance at a $180{ }^{\circ} \mathrm{C}$ desorption temperature (a, b) over 5 days. The illustration shows day 1 (a) and day 5 (b). TSA performance at a $152{ }^{\circ} \mathrm{C}$ desorption temperature $(\mathrm{c}, \mathrm{d})$ is shown over 7 days, with the

illustration highlighting days 2 (c) and 7 (d). Adsorption cycles are marked in green; heating up and desorption are marked in red. Cool down cycles are marked in blue

was adsorbed with an efficiency of over $99 \%$ after the first cycle. During the following cycles, an efficiency loss was seen, reducing tar removal to $92 \%$. This loss of efficiency was explained by a higher tar injection caused by the syringe pump. Over time, regeneration of the adsorbent was observed. By the seventh day, a tar removal efficiency of $95 \%$ was measured. A total of $1.6 \mathrm{~m}^{3}$ of gas per $1 \mathrm{~m}^{3}$ of flush gas $\left(\mathrm{N}_{2}\right.$, off-gas) could be cleaned with this setup. However, the clean-to-flush gas ratio can be further increased by improving heat management of the system. Displacement effects for the TSA were not considered in this work, as only the sum of tar was detected.

Both experiments showed good tar removal efficiency. During the heat up and desorption phase, a low flush gas flow was adjusted. During the adsorption phase, a higher carrier gas flow was adjusted. During the cooling down phase, which lasted extraordinary long due to the cool down process of the lab oven, the flush gas flow was turned off.

Comparing the results of the two investigated TSA processes showed that a desorption temperature of $180^{\circ} \mathrm{C}$ resulted in higher tar adsorption during the adsorption phase. Table 4 shows the outlet tar composition after TSA test runs at desorption temperatures of $152^{\circ} \mathrm{C}$ and $180^{\circ} \mathrm{C}$. The overall tar content after adsorption was higher with a desorption temperature of $152{ }^{\circ} \mathrm{C}$. In particular, the naphthalene content in the gas increased the tar dew point, which led to condensation temperatures between -10.8 and $-2.8^{\circ} \mathrm{C}$ after the adsorber, under atmospheric pressure conditions. If $180^{\circ} \mathrm{C}$ was used as the desorption temperature, a lower tar dew point, between 14.3 and $-9.4{ }^{\circ} \mathrm{C}$, resulted, which was mainly influenced by the lower amount of naphthalene, exhibiting better desorption at elevated temperatures. However, both desorption temperatures showed good results in terms of tar adsorption, enabling both temperatures to be used for the described tar removal TSA.

Table 4 Exhaust gas composition and tar dew point at atmospheric pressure conditions after the adsorption process with 152 and $180{ }^{\circ} \mathrm{C}$ desorption temperatures

\begin{tabular}{lll}
\hline & $152{ }^{\circ} \mathrm{C}$ & $180{ }^{\circ} \mathrm{C}$ \\
\hline Thiophene $\left(\mathrm{mg} / \mathrm{m}^{3}{ }_{(\mathrm{STP})}\right)$ & $1.3 \ldots 2.5$ & $0.3 \ldots 1.4$ \\
Toluene $\left(\mathrm{mg} / \mathrm{m}^{3}{ }_{(\mathrm{STP})}\right.$ & $572 \ldots 1098$ & $429 \ldots 873$ \\
Styrene $\left(\mathrm{mg} / \mathrm{m}^{3}{ }_{(\mathrm{STP})}\right)$ & $9 \ldots 40$ & $6 \ldots 12$ \\
Naphthalene $\left(\mathrm{mg} / \mathrm{m}^{3}{ }_{(\mathrm{STP})}\right)$ & $10 \ldots 29$ & $6 \ldots 12$ \\
Tar dew point $\left({ }^{\circ} \mathrm{C}\right)[39]$ & $-10.8 \ldots-2.8$ & $-14.3 \ldots-9.4$ \\
\hline
\end{tabular}




\section{Conclusion and outlook}

Adsorption-based gas cleaning for syngas applications was developed. Due to economic considerations, the gas cleaning setup, described in Fig. 1, was redesigned to replace the "cold" biodiesel scrubber. Adsorption isotherms and isobars were measured to obtain the optimal operation conditions for expected tar loading in the gas. Desorption experiments were carried out in TGA to determine the optimal desorption temperature of $152{ }^{\circ} \mathrm{C}$. Based on these data, a TSA was designed and tested in a single reactor setup, switching between adsorption and desorption operations. A tar removal efficiency of at least $95 \%$ was confirmed during the test runs. The laboratory TSA was operated with clean gas to a flush gas efficiency of

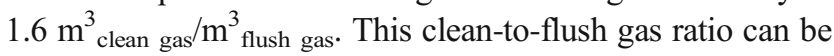
increased significantly by applying a two-reactor TSA with improved heat management if the TSA is scaled up and a longer adsorption time is adjusted. Comparing the gathered results with a biodiesel scrubber operated at low temperatures between 0 and $5{ }^{\circ} \mathrm{C}$, similar results were obtained if 11 of biodiesel was used per $1 \mathrm{~m}^{3}$ STP of syngas, which would lead to a huge increase regarding gas cleaning and respective plant operation costs. In further work, the replacement effects observed in this study will be analyzed in more detail, and an upscaling of the plant will be done, to enable operation with industrial syngas.

Funding The research leading to these results received funding from the COMET program managed by the Austrian Research Promotion Agency under grant number 869341 . The program was co-financed by the Republic of Austria and the Federal Provinces of Lower Austria, Styria and Vienna. Co-funding from the industry partners is highly acknowledged.

Data availability Not applicable

\section{Compliance with ethical standards}

Conflicts of interest The authors declare that they have no conflict of interest.

Code availability Not applicable

\section{References}

1. Li C, Suzuki K (2008) Renew Sust Energ Rev 13:594-604

2. Nguyen H, Seemann M, Thunman H (2018) Fate of polycyclic aromatic hydrocarbons during tertiary tar formation in steam gasification of biomass. Energy Fuel 32:3499-3509

3. Devi JL, Ptasinksik J, Janssen FJJG (2003) A review of the primary measures for tar elimination in biomass gasification processes. Biomass Bioenergy 24:125-140

4. Larsson A, Seemann M, Neves D, Thunman H (2013) Fuel Energy 11:6665-6680
5. Evans RJ, Milne TA (1997) Chemistry of tar formation and maturation in the thermochemical conversion of Biomass. Springer, Dodrecht, pp 803-816

6. Evans RJ, Milne TA (1998) Fuel and energy abstracts 39

7. Morf P, Hasler P, Nussbaumer T (2002) Mechanisms and kinetics of homogeneous secondary reactions of tar from continuous pyrolysis of wood chips. Fuel 81:843-853

8. Cypress R (1987) Aromatic hydrocarbons formation during coal pyrolysis. Fuel Process Technol 15:1-15

9. Nelson PF, Hüttinger KJ (1986) The effect of hydrogen pressure and aromatic structure on methane yields from the hydropyrolysis of aromatics. Fuel 65:354-361

10. Wanzl W (1988) Chemical reaction in thermal decomposition of coal. Fuel Process Technol 20:317-336

11. Wolfesberger U, Aigner I, Hofbauer H (2009) Tar content and composition in producer gas of fluidized bed gasification of wood-Influence of temperature and pressure. Environ Prog Sustain Energy 28:372-379

12. Milne TA, Evans RJ, Abatzoglou N (1998) Biomass gasifier "tars": their nature, formation, and conversion. Technical Report, National Renewable Energy Laboratory

13. Jeevanandam P, Klabunde KJ, Tetzler SH (2005) Adsorption of thiophenes out of hydrocarbons using metal impregnated nanocrystalline aluminum oxide. Microporous Mesoporous Mater 79:101110

14. Yu C, Qiu JS, Sun YF, Li XH, Chen G, Zhao ZB (2008) Adsorption removal of thiophene and dibenzothiophene from oils with activated carbon as adsorbent: effect of surface chemistry. J Porous Mater 15:151-157

15. Edinger P, Grimekis D, Panopoulos K, Karellas S, Ludwig C (2017) Adsorption of thiophene by activated carbon: a global sensitivity analysis. J Environ Chem Eng 5:4173-4184

16. Phuphuakrat T, Namioka T, Yoshikawa K (2010) Tar removal from biomass pyrolysis gas in two-step function of decomposition and adsorption. Appl Energy 87:2203-2211

17. Hu X, Hanaoka T, Sakanishi K, Shinagawa T, Matsui S, Tada M, Iwasaki T (2007) Removal of tar model compounds produced from biomass gasification using activated carbons. J Jpn Inst Energy 86: 707-711

18. Mastral AM, Garcia T, Callen MS, Navarro MV, Galban J (2001) Assessement of phenanthrene removal from hot gas by porous carbons. Energy Fuel 15:1-7

19. Thunman H, Seemann M, Berdugo Vilches T, Maric J, Pallares D, Ström H, Berndes G, Knutsson P, Larsson A, Breitholtz C, Santos O (2018) Advanced biofuel production via gasification - lessons learned from 200 man-years of research activity with Chalmers' research gasifier and the GoBiGas demonstration plant. Energy Sci Eng 6:6-34

20. Thunman H, Gustavsson C, Larsson A, Gunnarsson I, Tengberg F (2018) Energy Sci Eng 7:217-229

21. Bardolf R (2017) Optimierung eines Produktgaswäschers bei der Biomassedampfvergasung im Zweibettwirbelschichtverfahren. Dissertation, TU Wien

22. Bolhàr-Nordenkampf $\mathrm{M}$, Rauch $\mathrm{R}$, Bosch $\mathrm{K}$, Aichernig $\mathrm{C}$, Hofbauer H (2002) 2nd Regional Conference on Energy Technology Towards a Clean Environment, Phuket

23. Loipersböck J, Lenzi M, Rauch R, Hofbauer H (2017) Hydrogen production from biomass: the behavior of impurities over a $\mathrm{CO}$ shift unit and a biodiesel scrubber used as a gas treatment stage. Korean J Chem Eng 34:2198-2203

24. Sauciuc A, Abusteif Z, Weber G, Potetz A, Rauch R, Hofbauer H, Schaub G, Dumitrescu L (2012) Influence of operating conditions on the performance of biomass-based Fischer-Tropsch synthesis. Biomass Conv Bioref 2:253-263

25. Chianese S, Loipersböck J, Malits M, Rauch R, Hofbauer H, Molino A, Musmarra D (2015) Hydrogen from the high 
temperature water gas shift reaction with an industrial $\mathrm{Fe} / \mathrm{Cr}$ catalyst using biomass gasification tar rich synthesis gas. Fuel Process Technol 132:39-48

26. Pröll T, Siefert I, Friedl A, Hofbauer H (2005) Removal of NH3 from biomass gasification producer gas by water condensing in an organic solvent scrubber. Ind Eng Chem Res 44:1576-1584

27. Loipersböck J, Luisser M, Müller S, Hofbauer H, Rauch R (2018) Experimental demonstration and validation of hydrogen production based on gasification of lignocellulosic feedstock. Chemengineering 2:61

28. Baker EG, Brown MD, Elliot DC, Mudge LK (1988) AIChe Summer National Meeting

29. Elliot DS (1988) ACS symposium series 376

30. Gil J, Corella J, Aznar MP, Caballero MA (2008) Biomass Bioenergy 17:389-403

31. Ponzio A, Kalisz S, Blasiak W (2006) Effect of operating conditions on tar and gas composition in high temperature air/steam gasification (HTAG) of plastic containing waste. Fuel Process Technol 87:223-233

32. Kübel M (2007) Teerbildung und Teerkonversion bei der Biomassevergasung - Anwendung der nasschemischen Teerbestimmung nach CENStandard, Cuvillier Verlag
33. Neeft JPA, Knoef HAM, Onaji P (1999) Behaviour of tar in biomass gasification system. Tar related problems and their solutions, EWAB Program Report

34. Dayton D (2002) A review of the literature on catalytic biomass tar destruction. National Renewable Energy Laboratory

35. Bathen D (1998) Untersuchungen zur Desorption durch Mikrowellenenergie, VDI-Fortschritt-Bericht Reihe, 3 VDI Verlag Düsseldorf

36. Ruthven DM (1984) Principles of adsorption and adsorption processes. Wiley, New York

37. Gemmingen UV, Mersmann A, Schweighart P (1996) Kap. Adsorptionsapparate, in Weiß (ed) Thermisches Trennen, Deutscher Verlag für Grundstoffindustrie, Stuttgart

38. Dang S, Zhao L, Yang Q, Zheng M, Zhang J, Gao J, Xu C (2017) Competitive adsorption mechanism of thiophene with benzene in FAU zeolite: The role of displacement. Chem Eng J 328:172-185

39. ECN.TNO (2020) Classification System. Thersites, the ECN.TNO tar dew point site, http://www.thersites.nl/completemodel.aspx. Accessed 11 February 2020

Publisher's Note Springer Nature remains neutral with regard to jurisdictional claims in published maps and institutional affiliations. 